\title{
Intraday Electricity Pricing of Night Contracts
}

\author{
Marcel Kremer ${ }^{1, * \mathbb{D}}$, Rüdiger Kiesel ${ }^{1}$ and Florentina Paraschiv ${ }^{2,3}$ \\ 1 Chair for Energy Trading and Finance, University of Duisburg-Essen, Universitätsstraße 12, \\ 45141 Essen, Germany; ruediger.kiesel@uni-due.de \\ 2 NTNU Business School, Norwegian University of Science and Technology, 7491 Trondheim, Norway; \\ florentina.paraschiv@ntnu.no \\ 3 Institute for Operations Research and Computational Finance, University of St. Gallen, Bodanstrasse 6, \\ CH-9000 St. Gallen, Switzerland \\ * Correspondence: marcel.kremer@uni-due.de
}

Received: 31 July 2020; Accepted: 27 August 2020; Published: 1 September 2020

\begin{abstract}
This paper investigates the intraday electricity pricing of 15-min. contracts in night hours. We tailor a recently introduced econometric model with fundamental impacts, which is successful in describing the pricing of day contracts. Our estimation results show that the mean reversion and the positive price impact of neighboring contracts are generic features of the price formation process on the intraday market, independent of the time of day. Intraday auction prices have higher explanatory power for the pricing of night than day contracts, particularly, for the first and last 15-min. contract in a night hour. Intradaily updated forecasts of wind power infeed are the only significant fundamental factors for intraday electricity prices at night. Neither expected conventional capacities nor the slope of the merit order curve contribute to explaining price dynamics. Overall, we conclude that fundamentals lose in importance in night hours and the 15-min. intraday market is rather driven by price information.
\end{abstract}

Keywords: intraday electricity market; econometric modeling; night contracts; 15-min. contracts; fundamentals; renewable power forecasts

JEL Classification: C22; C24; C55; G10; Q20; Q21; Q40; Q41; Q42

\section{Introduction}

En route towards a sustainable energy future and a low-carbon economy, the expansion of renewable energy sources is promoted vigorously throughout the world. In Germany, for instance, renewable electricity generation increased from 105 TWh (17\% of gross electricity production) in 2010 to 244 TWh (40\% of gross electricity production) in 2019 [1]. As electricity infeed from intermittent renewable energy sources, like wind and solar energy, is highly volatile, energy supply companies wish to market renewable power over short delivery periods and at short notice. Additionally, market participants require automated trading strategies that are based on fundamental supply and demand factors to optimally trade their renewable and conventional power infeed.

The most short-term power market in Germany is the continuous intraday market, where 60-, 30-, and 15-min. supply contracts are tradable until $5 \mathrm{~min}$. before delivery. As such, intraday electricity markets are designed to satisfy the needs of energy suppliers and help alleviate imbalances between power supply and demand. Therefore, they play a key role in maintaining the overall stability of the electric power system. Moreover, intraday markets allow to balance forecast errors of renewable power production as close to the actual electricity delivery as possible. The total yearly trading volume on the German/Austrian intraday power market increased nearly sixfold from 10 TWh in 2010 to 57 TWh in 2019 [2,3]. In light of Germany's energy transition target of a share of 65\% renewables in 
gross electricity consumption by 2030 [4], the trading volumes on the intraday market are expected to rise further.

This article explores the intraday electricity pricing of 15-min. contracts during night hours, which has not been analyzed in previous research hitherto. Empirical evidence suggests that 15-min. intraday prices exhibit a sawtooth-shaped hourly seasonality on average, on both the continuous intraday market $[5,6]$ and intraday auction [7]. While during the day, the hourly price seasonality can be explained by the electricity generation from solar energy, solar power supply cannot justify the seasonality pattern during night hours. At night, we explain the sawtooth-shaped hourly seasonality by the electricity demand profile in conjunction with the established hourly delivery positions from the day-ahead auction. This is the first time in the literature that the hourly price seasonality in night hours is explained in detail. Beyond the average behavior of 15-min. intraday prices, this paper sheds light on the intraday pricing process of night 15 -min. contracts at a more fine-grained level. Specifically, we investigate four research questions: (i) Which explanatory factors drive the intraday electricity trading of 15-min. contracts at night? (ii) How does the intraday pricing process of night contracts differ from the pricing of day contracts? (iii) How much of the trading at night is driven by fundamental supply and demand factors and how much can be ascribed to pure price information? (iv) Are there different pricing regimes on the intraday market depending on the slope of the merit order curve?

Our starting point is the work of [6], who develop an econometric price model with fundamental impacts for intraday electricity markets of daytime 15-min. contracts. We tailor their model to night contracts and examine to which extent it is suited to describe the pricing process at night. A comparison with their results obtained for morning, noon, and evening contracts allows us to derive generic features of the intraday price formation as well as discrepancies between the pricing of day and night contracts: Past, idiosyncratic price information, the price information of neighboring contracts, trading volumes, and intraday wind power forecasts play a significant role for electricity prices of night contracts. However, the intraday pricing process of night contracts does not depend on different regimes of the merit order curve, which is in contrast to the price dynamics of day contracts.

In recent years, the academic interest in understanding intraday electricity markets has consistently increased. However, the intraday pricing of night contracts has not been explicitly addressed in scientific research hitherto. Our paper fills this gap in the literature. The literature concerned with intraday electricity trading can be classified into five major strands: Refs. $[5,6,8,9]$ determine price drivers on the intraday market based on trading-related and fundamental factors; Refs. [10-13] examine the impact of renewable power generation and its forecast errors on intraday electricity prices; Refs. [14-17] derive optimal trading strategies for an agent who aims at marketing both renewable and conventional power on the intraday market; Refs. $[7,18,19]$ provide forecasting studies for intraday electricity prices; Refs. [20-22] model the market microstructure of the intraday market based on transaction and market order arrivals.

The intraday electricity trading of 15-min. contracts has scarcely been studied in the literature though. Ref. [5] present an econometric threshold model for 15-min. electricity prices in the continuous intraday market. They document an asymmetric impact of renewable power forecast changes on intraday prices with respect to the proportion of expected demand met by conventional power generation capacities. Ref. [6] refine their model and illustrate that the intraday pricing process depends on the regime of the merit order curve. Moreover, they identify prices of neighboring contracts as important price drivers of 15-min. intraday trading. Ref. [23] investigate the effect of introducing 15-min. contracts on the trading of hourly contracts. Their results indicate that prices of hourly contracts have dropped between $11 \%$ and $28 \%$. Ref. [24] analyze the price volatility of 15 -min. contracts traded in the intraday call auction and on the continuous intraday market. They find that varying demand and the variable renewable power production are significant explanatory factors for intraday volatility. Ref. [25] model and forecast realized volatility of 15-min. contracts traded on the German/Austrian intraday market. They show that decomposing realized volatility into its continuous 
and jump component improves the forecasting performance. Ref. [26] examine the economic benefits of precise 15-min. electricity price forecasts. They conclude that a "buy low, sell high" strategy combined with accurate price forecasting can yield decent profits.

This article extends previous research along a number of dimensions: first, and to the best of our knowledge, we present the first work studying the intraday electricity pricing of night contracts explicitly. In particular, this is the first article explaining the hourly price seasonality of 15-min. contracts during night hours in detail. Second, our tailor-made econometric model only entails ex-ante market knowledge and is, thus, inherently designed for applications in academia and practice. Third, we examine a unique data set of intradaily updated forecasts of wind power production; these data correspond to the same real-time forecasts market participants incorporate into their bidding strategies on the intraday market. Fourth, we provide the first comprehensive comparison of the intraday pricing process of day and night 15 -min. contracts.

This paper is organized, as follows: in Section 2, we lay out our data set and conduct an empirical analysis of the hourly seasonality of prices and volumes of 15-min. contracts in night hours. In Section 3, we present a tailor-made version of the econometric model by [6] for night contracts and the threshold regression. In Section 4, we calibrate the econometric model to market data and discuss our estimation results. We offer our conclusions in Section 5.

\section{Stylized Facts}

In this section, we present our data set and empirically analyze the hourly seasonality of intraday prices and volumes of night 15 -min. contracts.

\subsection{Data}

We examine high-frequency transaction data and linked fundamental supply and demand data of night 15-min. contracts traded on the German continuous intraday power market at EPEX SPOT SE. As night contracts, we consider 15-min. contracts delivering electricity in the time period between $10 \mathrm{PM}$ and $4 \mathrm{AM}$. Our observation period ranges from 1 January to 31 December 2015. As explanatory variables, we include intraday transaction prices and trading volumes of $15-\mathrm{min}$. contracts from the continuous intraday market, 15-min. intraday auction prices, intraday wind power forecasts, expected electricity demand (total load forecasts), and expected conventional generation capacities. As conventional energy sources, we include coal, garbage, gas, lignite, oil, other, pumped-storage, run-of-the-river, seasonal-store, uranium. A detailed description of the employed explanatory variables, including units, granularities, and sources, is provided in Table 1.

In 2015, the continuous intraday market for 15-min. contracts with delivery in Germany opens daily at $4 \mathrm{PM}$ and ends 45 and $30 \mathrm{~min}$. before the delivery of electricity begins, respectively. On 16 July 2015, EPEX SPOT SE reduced the lead time on the German continuous intraday power market from 45 to $30 \mathrm{~min}$. before delivery [27]. The lead time within the four German control zones was further reduced to $5 \mathrm{~min}$. before delivery on 14 June 2017 [28]. The intraday transaction data (prices and volumes) from the continuous trading session are provided with a maximum time resolution of $1 \mathrm{~min}$.; this does not mean that one transaction is observed every minute, but it can take several minutes until the next transaction is conducted. If multiple transactions are executed in the same minute, then we calculate the volume-weighted average price for that trading minute. The German 15-min. intraday auction takes place daily at $3 \mathrm{PM}$ and its results, which is, market clearing prices and volumes, are published from 3:10 PM onwards. Throughout this paper, we denote a 15-min. contract by $\mathrm{H} h \mathrm{Q} q$, where $h=0, \ldots, 23$ and $q=1, \ldots, 4$; for example, contract H1Q1 refers to the delivery period 1:00-1:15 AM.

The intraday wind power forecasts are the same real-time wind forecasts as available to market participants on the intraday market. Each wind forecast update contains a forecast time series of wind power generation in Germany for the subsequent eight days in a 15-min. time resolution; every 15 min., a new wind forecast update time series is received. To the best of our knowledge, 
intraday renewable power forecasts and their impact on intraday electricity prices have only been studied by [5,6]; Ref. [29] simulate and predict the evolution of intraday renewable forecasts.

Table 1. Summary of explanatory variables, granularities, detailed descriptions and data sources. Variables indexed by $t$ vary over the continuous intraday trading session of a 15-min. contract.

\begin{tabular}{|c|c|c|}
\hline $\begin{array}{l}\text { Variable [Unit] } \\
\text { (Granularity) }\end{array}$ & Description & Source \\
\hline $\begin{array}{l}\text { Transaction price } P_{t} \\
\text { [EUR/MWh] } \\
(1-\text { min.) }\end{array}$ & $\begin{array}{l}\text { Transaction price of } 15-\mathrm{min} \text {. contracts traded } \\
\text { on the German continuous intraday power } \\
\text { market at EPEX SPOT SE }\end{array}$ & $\begin{array}{l}\text { European Energy Exchange } \\
\text { AG [30] }\end{array}$ \\
\hline $\begin{array}{lll}\text { Trading } & \text { volume } & V_{t} \\
\text { [MW] } & & \\
(1-\min ) & & \\
\end{array}$ & $\begin{array}{l}\text { Trading volume of } 15-\mathrm{min} \text {. contracts traded } \\
\text { on the German continuous intraday power } \\
\text { market at EPEX SPOT SE }\end{array}$ & $\begin{array}{l}\text { European Energy Exchange } \\
\text { AG [30] }\end{array}$ \\
\hline $\begin{array}{l}\text { Auction price } P^{\text {Auc }} \\
\text { [EUR/MWh] } \\
\text { (quarter-hourly) }\end{array}$ & $\begin{array}{l}\text { Market clearing price of } 15-\mathrm{min} \text {. contracts } \\
\text { traded in the German } 15-\mathrm{min} \text {. intraday } \\
\text { auction at EPEX SPOT SE (published: daily } \\
\text { after 3:10 PM) }\end{array}$ & $\begin{array}{l}\text { European Energy Exchange } \\
\text { AG [31] }\end{array}$ \\
\hline $\begin{array}{l}\text { Wind power forecast } w_{t} \\
\text { [GW] } \\
\text { (quarter-hourly) }\end{array}$ & $\begin{array}{l}\text { Intradaily updated forecast of wind power } \\
\text { generation for each quarter-hour on the } \\
\text { delivery day in Germany }\end{array}$ & EWE TRADING GmbH [32] \\
\hline $\begin{array}{l}\text { Expected demand } l \\
\text { [GW] } \\
\text { (quarter-hourly) }\end{array}$ & $\begin{array}{l}\text { Day-ahead total load forecast for each } \\
\text { quarter-hour on the delivery day in Germany } \\
\text { (published: daily at } 10 \mathrm{AM} \text { ) }\end{array}$ & $\begin{array}{l}\text { European Network of } \\
\text { Transmission System } \\
\text { Operators for Electricity } \\
\text { Transparency Platform [33] }\end{array}$ \\
\hline $\begin{array}{l}\text { Expected conventional } \\
\text { capacity } c \\
{[G W]} \\
(\text { daily })\end{array}$ & $\begin{array}{l}\text { Expected daily average of available } \\
\text { generation capacity of conventional power } \\
\text { plants on the delivery day in Germany } \\
\text { (published: daily at } 10 \text { AM) }\end{array}$ & $\begin{array}{l}\text { European Energy Exchange } \\
\text { AG Transparency Platform } \\
\text { [34] }\end{array}$ \\
\hline
\end{tabular}

\subsection{Hourly Seasonality}

We perform an empirical analysis of the hourly seasonality of intraday prices and volumes of 15-min. contracts in line with $[5,6]$. Here, we particularly concentrate on 15-min. contracts delivering electricity during night hours, which are not the focus of the latter studies. Figure 1 displays the volume-weighted average transaction price and the total trading volume of $15-\mathrm{min}$. contracts during off-peak hours for summer and winter. We identify a distinct hourly seasonality of both 15-min. intraday prices and volumes. The hourly seasonality maintains for unweighted average transaction prices as the seasonal averages of unweighted and volume-weighted average prices differ by approximately $2 \%$ only.

The hourly seasonality of volume-weighted average prices shows a sawtooth-like shape: For contracts H20Q1-H1Q4, the average price declines from the first 15-min. contract with the highest average price to the last 15-min. contract with the lowest average price within each hour. Conversely, for contracts H4Q1-H6Q4, the lowest average price is observed for the first 15-min. contract which increases to the highest average price for the last 15-min. contract in a given hour. Overall, average prices are fairly similar in summer and winter. The largest deviations are present for hours $\mathrm{H} 7$ and $\mathrm{H} 20$ as a result of varying times of sunrise and sunset between summer and winter.

Coincidently, total trading volumes exhibit a U-shaped hourly seasonality pattern: The first and last 15-min. contract within each hour entail larger trading volumes, while lower trading volumes are observed for the second and third 15-min. contract in that hour. Total trading volumes are particularly low for contracts H0Q1-H5Q4 during off-peak hours and overall very similar in summer and winter.

The hourly seasonality of 15-min. prices and volumes and its change around 3 AM can be explained by the quarter-hourly electricity demand profile in conjunction with the trading of hourly 
contracts in the day-ahead auction: From evening until after midnight (8 PM-2 AM), electricity demand continuously declines in each quarter-hour of a given hour in the wake of human activity. Energy supply companies first market their within-day generation on the day-ahead market by selling hourly contracts and produce the hourly average accordingly. The largest discrepancies between the decreasing quarter-hourly demand and the constant hourly supply is present at the beginning and at the end of each hour, respectively. Power suppliers thus produce too little electricity in the first quarter-hour and too much in the last quarter-hour of an hour io satisfy the quarter-hourly demand profile. Hence, they have to compensate the electricity shortfall in the first quarter-hour by purchasing large volumes of 15-min. contracts (buy pressure) and offset the electricity surplus in the last quarter-hour by selling high volumes of 15-min. contracts (sell pressure). As a result, the average 15-min. prices decrease within an hour.

The discontinuity between the low average price of the last 15-min. contract in a given hour and the high average price of the first 15-min. contract in the next hour is induced by trading hourly contracts day-ahead: Due to the established hourly position, there is a sharp transition from high sell pressure at the end of a given hour to high buy pressure at the beginning of the next hour.

In the early morning hours (4-7 AM), after electricity demand has reached its lowest level (around 3 AM in Germany), the demand increases in each quarter-hour of an hour following human activity. Thus, there is sell pressure in the first and buy pressure in the last quarter-hour of an hour. Consequently, the hourly seasonality pattern is reversed. The existence of buy and sell pressure at the beginning and the end of an hour is supported by the U-shaped hourly seasonality of trading volumes.

Eventually, we argue that (i) the electricity demand profile determines the slope of the sawtooth-shape within an hour and (ii) established hourly positions from the day-ahead auction are responsible for the discontinuity between the average price of the last and first 15-min. contract of two consecutive hours.
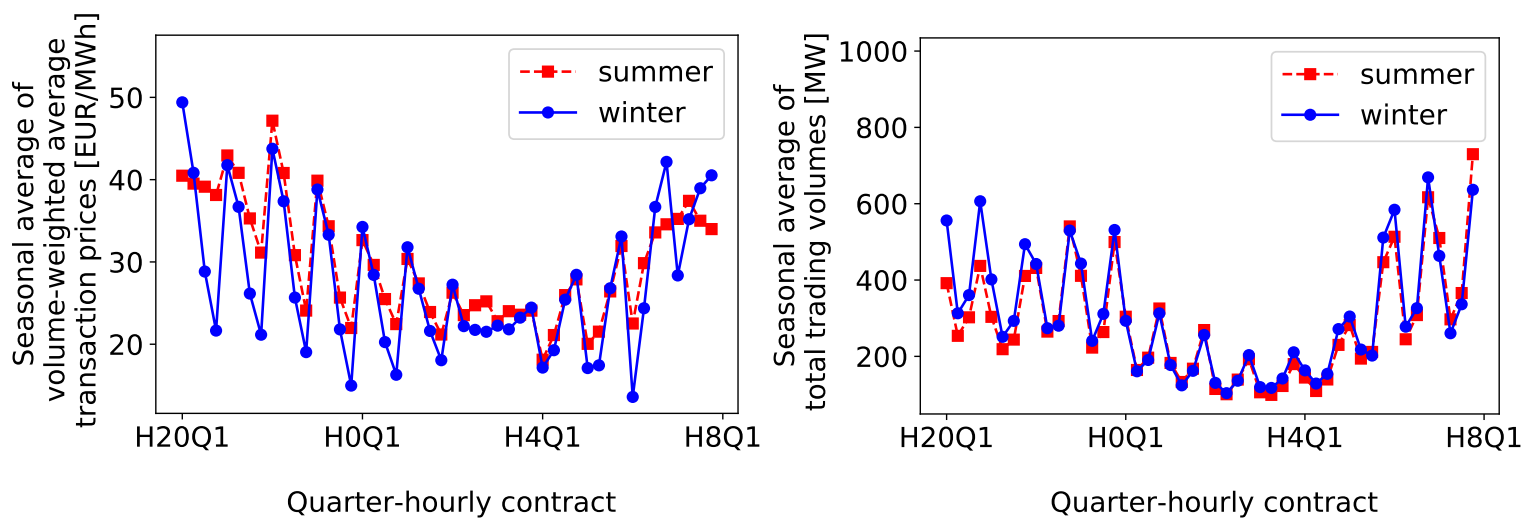

Figure 1. Volume-weighted average transaction price ( left) and total trading volume ( right) of 15-min. contracts during off-peak hours averaged over summer (red) and winter (blue).

\section{Methodology}

In this section, we present a tailor-made econometric model with fundamental impacts for night contracts as well as a threshold regression to calibrate our model to market data.

\subsection{Econometric Model}

We employ a modified version of the econometric model for intraday price changes of 15-min. contracts suggested by [6]. The modification for night contracts excludes solar power forecast changes and includes expected conventional capacities in line with the electricity generation mix during night hours. For a given 15 -min. contract $i=1, \ldots, 96$, the model specification reads 


$$
\begin{aligned}
\Delta P_{t}^{(i)}= & \alpha_{0}^{(i)}+\sum_{\tau=1}^{m} \alpha_{\tau}^{(i)} \Delta P_{t-\tau}^{(i)}+\sum_{\substack{j=-n, j \neq 0}}^{n} \beta_{j}^{(i)} \Delta P_{t}^{(i+j)}+\eta_{1}^{(i)} \xi^{(i)}+\eta_{2}^{(i)} P^{\mathrm{Auc},(i)}+\eta_{3}^{(i)} V_{t}^{(i)} \\
& +\eta_{4}^{(i)} \Delta w_{t}^{n,(i)}+\eta_{5}^{(i)} \Delta w_{t}^{p,(i)}+\eta_{6}^{(i)} c^{(i)}+\eta_{7}^{(i)} \sqrt{\Delta t^{(i)}}+\varepsilon_{t}^{(i)}
\end{aligned}
$$

where $\Delta P_{t}^{(i)}=P_{t}^{(i)}-P_{t-1}^{(i)}$ denotes the transaction price change between times $t$ and $t-1, \Delta P_{t}^{(i+j)}$ the last observed price change at time $t$ of neighboring contract $i+j, \xi^{(i)}$ the slope of the merit order curve, $P$ Auc, $(i)$ the 15 -min. intraday auction price, $V_{t}^{(i)}$ the trading volume at time $t, \Delta w_{t}^{n,(i)}=$ $\min \left(\Delta w_{t}^{(i)}, 0\right)$ and $\Delta w_{t}^{p,(i)}=\max \left(\Delta w_{t}^{(i)}, 0\right)$ negative and positive wind power forecast changes, respectively, where $\Delta w_{t}^{(i)}=w_{t}^{(i)}-w_{t-1}^{(i)}$ is the last available wind power forecast change at time $t, c^{(i)}$ the expected conventional capacity, $\Delta t^{(i)}$ the interarrival time between two successive transactions executed at times $t$ and $t-1$ of contract $i$, and $\varepsilon_{t}^{(i)} \stackrel{\text { iid }}{\sim} \mathcal{N}\left(0, \sigma^{2}\right)$ the error term.

The first sum presented in Equation (1) contains autoregressive price changes $\Delta P_{t-1}^{(i)}, \ldots, \Delta P_{t-m^{\prime}}^{(i)}$ where the number of lags $m$ is determined by partial autocorrelation. The second sum in Equation (1) comprises price changes $\Delta P_{t}^{(i+j)}$ of neighboring contracts $i \pm 1, \ldots, i \pm n$ of contract $i$ : We symmetrically include the latest price change of $n$ contracts with delivery before and $n$ contracts with delivery after contract $i$; e.g., if we model contract $i=\mathrm{H} 1 \mathrm{Q} 1$ and choose $n=2$, the latest price change of contracts H0Q3, H0Q4, H1Q2, H1Q3 is incorporated into the model. The intraday auction price $P^{\text {Auc, }(i)}$ does not vary over the continuous trading session, but is determined before continuous trading begins. Thus, $P^{\text {Auc, }(i)}$ serves as a first price reference for contract $i$ on the continuous intraday market. The model differentiates between positive and negative wind power forecast errors $\Delta w_{t}^{p,(i)}$ and $\Delta w_{t}^{n,(i)}$, respectively, as they have a contrary impact on electricity prices. The interarrival time $\Delta t^{(i)}$ controls for the fact that the intraday transaction data are not equally spaced in time. In particular, liquidity on the intraday electricity market increases and, thus, interarrival times decrease towards gate closure. as shown by $[6,17,21,35]$. This behavior is typical for financial markets whose underlying design corresponds to a forward market [see, e.g., [36] for a recent empirical study on the German electricity futures market].

The slope of the merit order curve $\xi^{(i)}$ is not directly given by empirical market data, but it has to be estimated. [6] suggest to estimate $\xi^{(i)}$ from the demand side based on intraday auction prices $P^{A u c,(i)}$ and expected demands, or total load forecasts, $\ell^{(i)}$ of contract $i$. The estimation procedure involves four steps:

1. make a scatter plot of intraday auction prices $P^{\text {Auc, }(i)}$ versus expected demands $\ell^{(i)}$;

2. fit the empirical merit-order-curve function $f(\ell)=\mathrm{e}^{a \ell+b}$ to the price-demand data;

3. compute the derivative $f^{\prime}(\ell)$ of the fitted merit-order-curve function; and,

4. $\quad$ substitute empirical demands $\ell^{(i)}$ to obtain merit-order-curve slopes $\xi^{(i)}=f^{\prime}\left(\ell^{(i)}\right)$.

The slope of the merit order curve $\xi^{(i)}$ does not vary during continuous trading and its value can be estimated before intraday market opening. The information conveyed by the expected conventional capacity $c^{(i)}$ and the slope of the merit order curve $\xi^{(i)}$ is not redundant, as the merit order curve is modeled from the demand side, whereas the conventional generation capacity is a supply-side explanatory factor (see [6] chap. 1, for a detailed discussion).

It is essential to point out that our econometric model (1) only involves ex-ante market information on the underlying price drivers to model intraday price changes. This is a valuable property of our model, in particular, from a trader's and practitioner's point of view. 


\subsection{Threshold Regression}

We use the threshold regression, or sample-split, model introduced by [37] with the aim of calibrating our econometric model (1) to market data. The threshold regression model splits the entire data set into two regimes and estimates a linear regression model in each regime separately.

Given an observed sample $\left\{y_{i}, \mathbf{x}_{i}, q_{i}\right\}_{i=1}^{n}$ of size $n$, where $y_{i}$ is the dependent variable, $\mathbf{x}_{i} \in \mathbb{R}^{m}$ the vector of independent variables, and $q_{i}$ the threshold variable, the threshold regression model reads

$$
\begin{aligned}
y_{i} & = \begin{cases}\boldsymbol{\theta}_{1}^{\prime} \mathbf{x}_{i}+\varepsilon_{i}, & \text { if } q_{i} \leq \gamma, \\
\boldsymbol{\theta}_{2}^{\prime} \mathbf{x}_{i}+\varepsilon_{i}, & \text { if } q_{i}>\gamma\end{cases} \\
& =\boldsymbol{\theta}_{1}^{\prime} \mathbf{x}_{i} \mathbb{1}\left\{q_{i} \leq \gamma\right\}+\boldsymbol{\theta}_{2}^{\prime} \mathbf{x}_{i} \mathbb{1}\left\{q_{i}>\gamma\right\}+\varepsilon_{i}, \quad i=1, \ldots, n .
\end{aligned}
$$

Here, $\gamma$ is the threshold parameter, $\boldsymbol{\theta}_{1}, \boldsymbol{\theta}_{2} \in \mathbb{R}^{m}$ are the regression parameter vectors, $\mathbb{1}$ is the indicator function, and $\varepsilon_{i} \stackrel{\text { iid }}{\sim} \mathcal{N}\left(0, \sigma^{2}\right)$ the error term. Hence, the threshold regression model splits the sample at a specific value $\gamma$ of the designated threshold variable $q_{i}$ and allows for the regression parameters in $\boldsymbol{\theta}_{1}, \boldsymbol{\theta}_{2}$ to change depending on the regime. The regression parameters $\boldsymbol{\theta}_{1}, \boldsymbol{\theta}_{2}, \boldsymbol{\gamma}$ can be estimated by least squares and jointly minimize the sum of squared errors function.

A prerequisite in the context of regime-switching threshold models is to test whether a threshold model specification is preferred over the alternative linear model. The threshold test used by [37] tests for a statistically significant threshold effect in the threshold, or sample-splitting, variable $q_{i}$ and it computes asymptotic $p$-values via bootstrapping.

A detailed description of the inference on and the estimation of the threshold and the regression parameters may be found in [6,37]. The threshold model can be tested and estimated using the $R$ package thrreg that was developed by [38].

\section{Estimation Results}

In this section, we estimate the parameters of our econometric model by the threshold regression and linear regression for all 15-min. contracts during night hours, which is, for contracts H22Q1-H3Q4.

\subsection{Threshold Regression}

We aim at re-estimating the econometric model (1) for night 15-min. contracts by the threshold regression described in Section 3.2 using the slope of the merit order curve $\xi$ as threshold variable in line with [6]. The merit-order-curve slope is used as threshold variable in order to distinguish between a flat and steep merit-order regime, in which the intraday pricing process behaves differently. They provide statistical evidence for a threshold effect in the merit-order-curve slope $\xi$ and, thus, different pricing regimes, for morning, noon, and evening contracts.

As a prerequisite, we test for a threshold effect in the merit-order-curve slope $\xi$ for all night 15-min. contracts H22Q1-H3Q4. In general, the threshold test does not show evidence for a statistically significant threshold effect in the slope of the merit order curve at the $10 \%$ level for all contracts. The reason for the poor statistical significance of the threshold test is that the merit order curve is relatively flat during night hours in the wake of generally low demand. Therefore, the merit-order-curve slope does not allow distinguishing between a flat and steep merit-order regime in night hours. Consequently, a linear model specification is preferred over the alternative threshold model for the intraday pricing process of night contracts.

\subsection{Linear Regression}

We estimate our econometric model (1) for 15-min. contracts in night hours by linear regression using ordinary least squares, as there is no statistical evidence for a threshold model specification. Here, we analyze a representative selection of night contracts, that is, 15-min. contracts in hours $\mathrm{H} 1$ and H3, Q1-Q4 each. We correct for heteroscedasticity and autocorrelation of residuals via Newey-West, 
or heteroscedasticity and autocorrelation consistent (HAC), standard errors. The estimation results of all 15-min. contracts in hours $\mathrm{H} 1$ and $\mathrm{H} 3$ are presented in Tables 2 and 3, respectively. As the results in both hours are very similar, we focus our in-depth discussion on the findings of hour H1. The adjusted $R^{2}$ ranges between $20 \%$ and $29 \%$.

Table 2. Estimation results of the econometric model (1) for intraday price changes $\Delta P_{t}$ of 15 -min. contracts H1Q1-4.

\begin{tabular}{|c|c|c|c|c|c|}
\hline \multicolumn{4}{|c|}{ H1Q1 } & \multicolumn{2}{|c|}{ H1Q2 } \\
\hline Variable & Estimate & Std Error & Variable & Estimate & Std Error \\
\hline Const & 0.160 & (0.808) & Const & -0.263 & (0.890) \\
\hline$\xi$ & -0.378 & (2.508) & $\xi$ & 2.251 & (3.204) \\
\hline$\Delta P_{t-1}$ & $-0.393^{* * *}$ & $(0.024)$ & $\Delta P_{t-1}$ & $-0.406^{* * *}$ & (0.028) \\
\hline$\Delta P_{t-2}$ & $-0.201^{* * *}$ & $(0.020)$ & $\Delta P_{t-2}$ & $-0.196^{* * *}$ & $(0.022)$ \\
\hline$\Delta P_{t-3}$ & $-0.098^{* * *}$ & $(0.014)$ & $\Delta P_{t-3}$ & $-0.079^{* * *}$ & (0.022) \\
\hline$\Delta P_{t}^{(i-2)}$ & $0.022 *$ & $(0.012)$ & $\Delta P_{t}^{(i-2)}$ & 0.014 & $(0.010)$ \\
\hline$\Delta P_{t}^{(i-1)}$ & $0.014^{* * *}$ & $(0.005)$ & $\Delta P_{t}^{(i-1)}$ & $0.124^{* * *}$ & $(0.023)$ \\
\hline$\Delta P_{t}^{(i+1)}$ & $0.157^{* * *}$ & $(0.032)$ & $\Delta P_{t}^{(i+1)}$ & $0.119^{* * *}$ & $(0.017)$ \\
\hline$\Delta P_{t}^{(i+2)}$ & $0.033^{* *}$ & $(0.016)$ & $\Delta P_{t}^{(i+2)}$ & 0.011 & $(0.013)$ \\
\hline$P^{\text {Auc }}$ & $0.020^{*}$ & $(0.016)$ & $P^{\text {Auc }}$ & 0.003 & $(0.017)$ \\
\hline$V_{t}$ & $-0.054^{* * *}$ & (0.007) & $V_{t}$ & $-0.050^{* * *}$ & (0.013) \\
\hline$\Delta w_{t}^{n}$ & -0.059 & $(0.261)$ & $\Delta w_{t}^{n}$ & $-1.073^{* * *}$ & (0.373) \\
\hline$\Delta w_{t}^{p}$ & $-2.085^{* * *}$ & $(0.246)$ & $\Delta w_{t}^{p}$ & $-1.177^{* * *}$ & $(0.250)$ \\
\hline$c^{-}$ & 0.000 & $(0.021)$ & $c^{l}$ & -0.009 & $(0.021)$ \\
\hline$\Delta t$ & $0.071^{* *}$ & $(0.032)$ & $\Delta t$ & 0.002 & $(0.040)$ \\
\hline \#Obs & 6649 & & \#Obs & 6421 & \\
\hline$R_{\text {adj }}^{2}$ & 0.224 & & $R_{\mathrm{adj}}^{2}$ & 0.203 & \\
\hline \multicolumn{4}{|c|}{ H1Q3 } & \multicolumn{2}{|c|}{ H1Q4 } \\
\hline Variable & Estimate & Std Error & Variable & Estimate & Std Error \\
\hline Const & -5.207 & $(4.508)$ & Const & -2.601 & $(1.632)$ \\
\hline$\xi$ & 39.743 & $(45.309)$ & $\xi$ & 10.180 & (11.879) \\
\hline$\Delta P_{t-1}$ & $-0.358^{* * *}$ & $(0.025)$ & $\Delta P_{t-1}$ & $-0.608^{* * *}$ & $(0.084)$ \\
\hline$\Delta P_{t-2}$ & $-0.177^{* * *}$ & (0.018) & $\Delta P_{t-2}$ & $-0.351^{* * *}$ & $(0.086)$ \\
\hline$\Delta P_{t-3}$ & $-0.101^{* * *}$ & (0.013) & $\Delta P_{t-3}$ & $-0.157^{* * *}$ & $(0.045)$ \\
\hline$\Delta P_{t}^{(i-2)}$ & 0.023 & $(0.014)$ & $\Delta P_{t}^{(i-2)}$ & $0.047^{* *}$ & $(0.021)$ \\
\hline$\Delta P_{t}^{(i-1)}$ & $0.078^{* * *}$ & $(0.020)$ & $\Delta P_{t}^{(i-1)}$ & $0.170^{* * *}$ & $(0.024)$ \\
\hline$\Delta P_{t}^{(i+1)}$ & $0.223^{* * *}$ & $(0.021)$ & $\Delta P_{t}^{(i+1)}$ & $0.169^{*}$ & $(0.094)$ \\
\hline$\Delta P_{t}^{(i+2)}$ & $0.033 *$ & $(0.018)$ & $\Delta P_{t}^{(i+2)}$ & 0.041 & $(0.027)$ \\
\hline$P^{\text {Auc }}$ & 0.016 & (0.012) & $P^{\text {Auc }}$ & $0.027 *$ & (0.016) \\
\hline$V_{t}$ & $0.030^{* * *}$ & $(0.010)$ & $V_{t}$ & 0.011 & (0.013) \\
\hline$\Delta w_{t}^{n}$ & $-1.032 * *$ & $(0.492)$ & $\Delta w_{t}^{n}$ & $-1.291^{* * *}$ & $(0.435)$ \\
\hline$\Delta w_{t}^{p}$ & $-1.090^{* * *}$ & $(0.229)$ & $\Delta w_{t}^{p}$ & $-0.621^{* *}$ & $(0.270)$ \\
\hline$c^{t}$ & 0.006 & $(0.024)$ & $c^{t}$ & 0.004 & (0.029) \\
\hline$\Delta t$ & $-0.078^{*}$ & $(0.040)$ & $\Delta t$ & $-0.180^{* * *}$ & (0.061) \\
\hline \#Obs & 7075 & & \#Obs & 7914 & \\
\hline$R_{\mathrm{adj}}^{2}$ & 0.207 & & $R_{\mathrm{adj}}^{2}$ & 0.290 & \\
\hline
\end{tabular}


Table 3. Estimation results of the econometric model (1) for intraday price changes $\Delta P_{t}$ of 15 -min. contracts H3Q1-4.

\begin{tabular}{|c|c|c|c|c|c|}
\hline \multicolumn{4}{|c|}{ H3Q1 } & \multicolumn{2}{|c|}{ H3Q2 } \\
\hline Variable & Estimate & Std Error & Variable & Estimate & Std Error \\
\hline Const & -1.352 & $(0.881)$ & Const & 0.865 & $(0.810)$ \\
\hline$\xi$ & -3.468 & $(4.834)$ & $\xi$ & -2.496 & (1.742) \\
\hline$\Delta P_{t-1}$ & -0.399 *** & $(0.020)$ & $\Delta P_{t-1}$ & $-0.365^{* * *}$ & $(0.024)$ \\
\hline$\Delta P_{t-2}$ & $-0.214^{* * *}$ & $(0.017)$ & $\Delta P_{t-2}$ & $-0.190^{* * *}$ & (0.019) \\
\hline$\Delta P_{t-3}$ & $-0.076^{* * *}$ & $(0.015)$ & $\Delta P_{t-3}$ & $-0.102^{* * *}$ & $(0.016)$ \\
\hline$\Delta P_{t}^{(i-2)}$ & $0.039 * *$ & $(0.018)$ & $\Delta P_{t}^{(i-2)}$ & 0.017 & $(0.014)$ \\
\hline$\Delta P_{t}^{(i-1)}$ & 0.014 & $(0.016)$ & $\Delta P_{t}^{(i-1)}$ & $0.119^{* * *}$ & $(0.017)$ \\
\hline$\Delta P_{t}^{(i+1)}$ & $0.140^{* * *}$ & $(0.020)$ & $\Delta P_{t}^{(i+1)}$ & $0.139^{* * *}$ & $(0.024)$ \\
\hline$\Delta P_{t}^{(i+2)}$ & $0.037^{* *}$ & $(0.017)$ & $\Delta P_{t}^{(i+2)}$ & $0.069^{* * *}$ & $(0.017)$ \\
\hline$P^{\text {Auc }}$ & $0.029^{* * *}$ & (0.009) & $P^{\text {Auc }}$ & 0.011 & (0.015) \\
\hline$V_{t}$ & $0.024^{* *}$ & $(0.010)$ & $V_{t}$ & $0.037^{* * *}$ & (0.011) \\
\hline$\Delta w_{t}^{n}$ & $-1.012^{* * *}$ & $(0.360)$ & $\Delta w_{t}^{n}$ & $-0.702^{* *}$ & $(0.283)$ \\
\hline$\Delta w_{t}^{p}$ & $-1.669^{* * *}$ & $(0.275)$ & $\Delta w_{t}^{p}$ & $-1.289^{* * *}$ & (0.181) \\
\hline$c$ & 0.031 & $(0.023)$ & $c$ & 0.009 & $(0.020)$ \\
\hline$\Delta t$ & 0.038 & $(0.036)$ & $\Delta t$ & -0.050 & $(0.033)$ \\
\hline \#Obs & 6357 & & \#Obs & 6309 & \\
\hline$R_{\mathrm{adj}}^{2}$ & 0.208 & & $R_{\mathrm{adj}}^{2}$ & 0.191 & \\
\hline \multicolumn{4}{|c|}{ H3Q3 } & \multicolumn{2}{|c|}{ H3Q4 } \\
\hline Variable & Estimate & Std Error & Variable & Estimate & Std Error \\
\hline Const & -0.227 & (1.475) & Const & -1.199 & $(0.913)$ \\
\hline$\xi$ & 4.497 & (8.890) & $\xi$ & -1.381 & $(2.122)$ \\
\hline$\Delta P_{t-1}$ & $-0.428^{* * *}$ & $(0.027)$ & $\Delta P_{t-1}$ & $-0.370^{* * *}$ & $(0.021)$ \\
\hline$\Delta P_{t-2}$ & $-0.174^{* * *}$ & $(0.016)$ & $\Delta P_{t-2}$ & $-0.166^{* * *}$ & $(0.018)$ \\
\hline$\Delta P_{t-3}$ & $-0.053^{* *}$ & $(0.021)$ & $\Delta P_{t-3}$ & $-0.057^{* * *}$ & (0.013) \\
\hline$\Delta P_{t}^{(i-2)}$ & $0.053^{* * *}$ & $(0.015)$ & $\Delta P_{t}^{(i-2)}$ & $0.023^{*}$ & $(0.014)$ \\
\hline$\Delta P_{t}^{(i-1)}$ & $0.072^{* * *}$ & $(0.017)$ & $\Delta P_{t}^{(i-1)}$ & $0.183^{* * *}$ & $(0.015)$ \\
\hline$\Delta P_{t}^{(i+1)}$ & $0.210^{* * *}$ & $(0.020)$ & $\Delta P_{t}^{(i+1)}$ & $0.049^{* * *}$ & $(0.016)$ \\
\hline$\Delta P_{t}^{(i+2)}$ & $0.075^{* * *}$ & $(0.028)$ & $\Delta P_{t}^{(i+2)}$ & $0.035^{* *}$ & $(0.016)$ \\
\hline$P^{\text {Auc }}$ & 0.005 & $(0.011)$ & $P^{\text {Auc }}$ & $0.021 *$ & $(0.011)$ \\
\hline$V_{t}$ & 0.015 & $(0.010)$ & $V_{t}$ & -0.010 & (0.008) \\
\hline$\Delta w_{t}^{n}$ & $-0.711^{* * *}$ & $(0.242)$ & $\Delta w_{t}^{n}$ & $-0.809^{* * *}$ & $(0.280)$ \\
\hline$\Delta w_{t}^{p}$ & $-1.063^{* * *}$ & (0.167) & $\Delta w_{t}^{p}$ & $-0.981^{* * *}$ & $(0.223)$ \\
\hline$c^{l}$ & -0.015 & $(0.020)$ & $c^{l}$ & 0.030 & $(0.024)$ \\
\hline$\Delta t$ & -0.042 & $(0.030)$ & $\Delta t$ & -0.027 & $(0.033)$ \\
\hline \#Obs & 6610 & & \#Obs & 7337 & \\
\hline$R_{\text {adj }}^{2}$ & 0.219 & & $R_{\mathrm{adj}}^{2}$ & 0.174 & \\
\hline
\end{tabular}

The estimated coefficients of the merit-order-curve slope $\xi$ are not statistically significant for all contracts in hour H1. Thus, the slope of the merit order curve does not add explanatory power to explaining intraday price changes $\Delta P_{t}$ of night contracts. In [6], $\xi$ is not a significant explanatory factor for intraday price changes within each price regime during morning, noon, and evening hours. Overall, we conclude that the merit-order-curve slope is neither suited as threshold variable nor as explanatory variable for explaining the intraday pricing process of night 15 -min. contracts.

The estimated coefficients of lagged price changes $\Delta P_{t-1}, \Delta P_{t-2}, \Delta P_{t-3}$ are highly statistically significant and negative for all contracts in hour H1. The higher-order autoregressive terms have less impact on the price change $\Delta P_{t}$ at time $t$. The negative coefficients of autoregressive price changes 
suggest mean reversion in the price formation process of 15-min. contracts at night. Ref. [6] find mean reversion in the pricing process of morning, noon, and evening contracts.

The estimated coefficients of price changes of neighboring contracts $\Delta P_{t}^{(i \pm 1)}, \Delta P_{t}^{(i \pm 2)}$ are highly statistically significant and positive for all contracts, while the coefficients of $\Delta P_{t}^{(i \pm 2)}$ exhibit less statistical significance. Hence, price information of neighboring contracts contribute to explaining intraday price changes of a given contract. The positive sign of the coefficients indicates that neighboring price time series are positively correlated. Furthermore, the impact of price changes of nearest neighbors $i \pm 1$ is greater than the impact of next-nearest neighbors $i \pm 2$ on the price changes of contract $i$. In particular, the price changes of 15-min. contracts Q1 and Q2, for one thing, and $\mathrm{Q} 3$ and $\mathrm{Q} 4$, for another thing, have the strongest effect on one another, which reflects the hourly seasonality of 15-min. electricity prices presented in Section 2.2. Ref. [6] document the same effect of neighboring contracts on morning, noon, and evening contracts. Additionally, ref. [19] find that neighboring contracts' price information improves the forecast accuracy of intraday electricity prices.

The estimated coefficients of the intraday auction price $P^{\text {Auc }}$ are statistically significant and positive for contracts $Q 1$ and $Q 4$. It seems plausible that the intraday auction price has a significant impact on intraday price changes $\Delta P_{t}$ of contracts at the beginning and end of the hour, since the (volume-weighted) average transaction price of Q1 and Q4 deviates the most from the average price during that hour due to the hourly price seasonality (see Section 2.2). Therefore, a first signal of the price level, as indicated through the intraday auction, is more important for the pricing process of contracts at the edge than in the middle of the hour. For morning, noon, and evening 15-min. contracts, however, $P^{\mathrm{Auc}}$ is not a significant intraday price driver [6]. Consequently, we find that the importance of intraday auction prices for the continuous intraday market is greater at night than during daytime.

The coefficients of trading volume $V_{t}$ are statistically significant for contracts Q1-Q3. For contracts Q1 and Q2, they are negative, whereas, for Q3 and Q4, they turn positive. This sign profile is sensible and it may be explained by the joint hourly seasonality of transaction prices and trading volumes described in Section 2.2: In the first half of the hour, intraday prices decrease due to sell pressure, as more electricity than the hourly average is generated; in the second half of the hour, intraday prices increase in the wake of buy pressure that arises from below-average electricity production.

The coefficients of negative and positive wind forecast changes $\Delta w_{t}^{n}$ and $\Delta w_{t}^{p}$ are highly statistically significant and negative for all contracts. The negative sign of both negative and positive wind forecast errors are economically meaningful: electricity prices should increase if less wind power infeed is anticipated and decrease if a higher share of wind power is expected. Hence, intraday forecast errors of wind power production add explanatory power to the intraday price formation of night contracts. The same result holds true for morning, noon, and evening contracts [6].

The coefficients of expected conventional capacities $c$ are not statistically significant for all contracts in hour H1. This is not surprising, as the empirical data on $c$ only comprise daily averages of expected conventional capacities. Thus, it not expected that $c$ significantly affects the continuous trading of 15-min. delivery periods. This finding underpins our expectation that conventional power generation is primarily marketed on the day-ahead market and, consequently, from the supply side, only wind power forecast errors are balanced on the intraday market.

The coefficients of interarrival times $\sqrt{\Delta t}$ are statistically significant for contracts Q1, Q3, Q4. They are positive for $\mathrm{Q} 1$ and $\mathrm{Q} 2$ and negative for $\mathrm{Q} 3$ and $\mathrm{Q} 4$. Let us consider the median significant coefficient of $\sqrt{\Delta t}$, which amounts to -0.078 and it is observed for contract Q3: if no transaction is conducted within one minute, the price is expected to decrease by roughly $0.08 \mathrm{EUR} / \mathrm{MWh}$ on average; if no transaction is conducted within $60 \mathrm{~min}$., the price is expected to decrease by $\sqrt{60} \times$ $0.078 \mathrm{EUR} / \mathrm{MWh} \approx 0.60 \mathrm{EUR} / \mathrm{MWh}$ on average. Depending on the time to gate closure, typical bid-ask spreads on the German intraday electricity market vary in the range of $1-7.5 \mathrm{EUR} / \mathrm{MWh}[17,35]$. Hence, the expected average price decrease resulting from $\sqrt{\Delta t}$ is comparatively small.

Eventually, we conclude that intraday trading of 15 -min. contracts at night is driven by trading-related variables (past, idiosyncratic price information, price information of neighboring 
contracts, intraday auction prices, trading volume) and wind power forecasts. However, the slope of the merit order curve and expected conventional capacities do not contribute to explaining the intraday pricing process at night. Consequently, intraday trading of night contracts is less driven by fundamentals than the trading of morning, noon, and evening contracts and the 15-min. market is more affected by pure price information.

\section{Conclusions}

This article investigates the intraday electricity pricing of night contracts. We examine high-frequency transaction data of 15-min. contracts traded on the German continuous intraday power market as well as linked fundamental supply and demand data. In particular, intradaily updated forecasts of wind power production are analyzed. We perform an empirical analysis of intraday prices and volumes of 15-min. contracts and identify a distinct hourly seasonality: While prices exhibit a sawtooth-shaped hourly seasonality on average, volumes show a U-shaped seasonality pattern. The hourly seasonality at night can be explained by the electricity demand profile along with the established hourly delivery positions from the day-ahead auction.

We tailor the recently introduced econometric model with fundamental impacts by [6] to night contracts, which has been proven to adequately describe the price dynamics of morning, noon, and evening contracts. As such, our model only incorporates ex-ante market knowledge. Our estimation results show strong evidence of mean reversion in the pricing process of night 15-min. contracts. Moreover, price changes of neighboring contracts have a statistically significant and positive effect on one another. These two findings are consistent with the results of morning, noon, and evening contracts, and, thus, independent of the time of day. Therefore, mean reversion and the positive price impact of neighboring contracts are generic features of the price formation mechanism on the intraday electricity market.

The 15-min. intraday auction price has explanatory power for pricing the first and last 15-min. contract within a night hour, and thereby serves as a first price signal for these contracts. Additionally, we infer that the importance of intraday auction prices is greater for intraday trading at night than during daytime. Moreover, the intraday trading volume adds explanatory power in explaining the intraday pricing process. On the side of fundamentals, intraday wind forecast changes have a statistically significant and expected negative effect on intraday prices. However, the slope of the merit order curve and expected conventional capacities do not contribute to the price dynamics of night contracts.

Overall, we conclude that intraday electricity pricing of night 15-min. contracts is predominantly determined by trading-related factors. Fundamentals play a subordinate role and 15-min. intraday trading is mainly driven by price information at night.

Our study is inherently designed for a number of applications in both academia and practice as it only involves ex-ante market information: first, our article paves the way to build trading strategies for the intraday trading of night contracts. In particular, we highlight the most important price drivers which should be taken into account in such strategies and how they affect intraday price changes. This knowledge also helps to enhance the optimal bidding behavior (optimal price, volume, and timing of a bid) of market participants on intraday markets. Moreover, our analysis lays the foundation for forecasting models for intraday electricity prices that are based on intradaily updated information on idiosyncratic and neighboring prices as well as wind power forecasts. Ultimately, our article conveys valuable implications for energy supply companies on the path towards the automation of intraday electricity trading. 
Author Contributions: Conceptualization, M.K., R.K., and F.P.; methodology, M.K., R.K., and F.P.; software, M.K.; validation, M.K., R.K., and F.P.; formal analysis, M.K.; investigation, M.K.; data curation, M.K.; writing-original draft preparation, M.K.; writing-review and editing, M.K., R.K., and F.P.; visualization, M.K.; supervision, R.K. and F.P.; project administration, M.K. All authors have read and agreed to the published version of the manuscript.

Funding: F.P. thanks the funding from Adolf Øiens Donasjonsfond Energizing New Computational Frontiers [grant number L10079] and the Isaac Newton Institute for Mathematical Sciences for its hospitality during the programme "The mathematics of energy systems" which was supported by the Engineering and Physical Sciences Research Council (EPSRC) [grant number EP/R014604/1]. This work has been performed within the +CityxChange (Positive City ExChange, https: / / cityxchange.eu/) project under the Smart Cities and Communities topic which was supported by the European Union's Horizon 2020 Research and Innovation programme [grant number 824260]. F.P.'s research was financially supported by Innosuisse as part of the activities within SCCER CREST.

Conflicts of Interest: The authors declare no conflict of interest.

\section{References}

1. BMWi. Energiedaten und -szenarien: Gesamtausgabe der Energiedaten-Datensammlung des BMWi. 2020. Available online: https:/ / www.bmwi.de/Redaktion/EN/Artikel/Energy/energy-data.html (accessed on 16 July 2020).

2. EPEX SPOT SE. Press Release: EPEX SPOT SE Accomplishes a Year of European Power Market Integration-Trading Volumes Rise Significantly in 2010. 2011. Available online: https:/ www.epexspot. com/sites/default/files/download_center_files/2011-01-12_EPEX_ANNUAL\%20PR_EN-D-FR.pdf (accessed on 16 July 2020).

3. EPEX SPOT SE. Press Release: EPEX SPOT Annual Market Review 2019 - New Trading Record on EPEX SPOT in 2019. 2020. Available online: https:/ / www.epexspot.com/sites/default/files/download_center_ files/200113_EPEX\%20SPOT_2019_Annual\%20Press\%20Release_.pdf (accessed on 16 July 2020).

4. International Energy Agency. Germany 2020 Energy Policy Review. 2020. Available online: https:/ / www.bmwi.de/Redaktion/DE/Downloads/G/germany-2020-energy-policy-review.pdf?_ blob $=$ publicationFile\&v $=4$ (accessed on 16 July 2020).

5. Kiesel, R.; Paraschiv, F. Econometric analysis of 15-min intraday electricity prices. Energy Econ. 2017, 64, 77-90. [CrossRef]

6. Kremer, M.; Kiesel, R.; Paraschiv, F. An econometric model for intraday electricity trading. Philos. Trans. R. Soc. A 2020, forthcoming.

7. Narajewski, M.; Ziel, F. Econometric modelling and forecasting of intraday electricity prices. J. Commod. Mark. 2019, 100107. [CrossRef]

8. Hagemann, S. Price determinants in the German intraday market for electricity: An empirical analysis. J. Energy Mark. 2015, 8, 21-45. [CrossRef]

9. Pape, C.; Hagemann, S.; Weber, C. Are fundamentals enough? Explaining price variations in the German day-ahead and intraday power market. Energy Econ. 2016, 54, 376-387. [CrossRef]

10. Ziel, F. Modeling the impact of wind and solar power forecasting errors on intraday electricity prices. In Proceedings of the 2017 14th International Conference on the European Energy Market (EEM), Dresden, Germany, 6-9 June 2017. [CrossRef]

11. Gürtler, M.; Paulsen, T. The effect of wind and solar power forecasts on day-ahead and intraday electricity prices in Germany. Energy Econ. 2018, 75, 150-162. [CrossRef]

12. Goodarzi, S.; Perera, H.N.; Bunn, D. The impact of renewable energy forecast errors on imbalance volumes and electricity spot prices. Energy Policy 2019, 134, 110827. [CrossRef]

13. Kulakov, S.; Ziel, F. The Impact of Renewable Energy Forecasts on Intraday Electricity Prices. 2019. Available online: https: / / arxiv.org/abs/1903.09641 (accessed on 16 July 2020).

14. Garnier, E.; Madlener, R. Balancing forecast errors in continuous-trade intraday markets. Energy Syst. 2015, 6, 361-388. [CrossRef]

15. Aïd, R.; Gruet, P.; Pham, H. An optimal trading problem in intraday electricity markets. Math. Financ. Econ. 2015, 10, 49-85. [CrossRef] 
16. Glas, S.; Kiesel, R.; Kolkmann, S.; Kremer, M.; von Luckner, N.G.; Ostmeier, L.; Urban, K.; Weber, C. Intraday renewable electricity trading: Advanced modeling and optimal control. In Progress in Industrial Mathematics at ECMI 2018; Springer International Publishing: Berlin/Heidelberg, Germany, 2019; pp. 469-475. [CrossRef]

17. Glas, S.; Kiesel, R.; Kolkmann, S.; Kremer, M.; Graf von Luckner, N.; Ostmeier, L.; Urban, K.; Weber, C. Intraday renewable electricity trading: Advanced modeling and numerical optimal control. J. Math. Ind. 2020, 10, 1-17. [CrossRef]

18. Uniejewski, B.; Marcjasz, G.; Weron, R. Understanding intraday electricity markets: Variable selection and very short-term price forecasting using LASSO. Int. J. Forecast. 2019, 35, 1533-1547. [CrossRef]

19. Janke, T.; Steinke, F. Forecasting the price distribution of continuous intraday electricity trading. Energies 2019, 12, 4262. [CrossRef]

20. Narajewski, M.; Ziel, F. Estimation and simulation of the transaction arrival process in intraday electricity markets. Energies 2019, 12, 4518. [CrossRef]

21. Graf von Luckner, N.; Kiesel, R. Modeling Market Order Arrivals on the Intraday Market for Electricity Deliveries in Germany with the Hawkes Process. 2020. Available online: https:/ / ssrn.com/abstract=3526795 (accessed on 16 July 2020).

22. Kramer, A.; Kiesel, R. Exogenous Factors for Order Arrivals on the Intraday Electricity Market. 2020. Available online: https:/ / ssrn.com/abstract=3540991 (accessed on 16 July 2020).

23. Märkle-Huß, J.; Feuerriegel, S.; Neumann, D. Contract durations in the electricity market: Causal impact of 15 min trading on the EPEX SPOT market. Energy Econ. 2018, 69, 367-378. [CrossRef]

24. Knaut, A.; Paschmann, M. Short-Term Price Volatility in Commodity Markets Explained—Evidence from the Power Sector. 2016. Available online: https://www.researchgate.net/publication/303973354_Shortterm_Price_Volatility_in_Commodity_Markets_Explained_-Evidence_from_the_Power_Sector (accessed on 16 July 2020).

25. Ciarreta, A.; Muniain, P.; Zarraga, A. Modeling and forecasting realized volatility in German-Austrian continuous intraday electricity prices. J. Forecast. 2017, 36, 680-690. [CrossRef]

26. Kath, C.; Ziel, F. The value of forecasts: Quantifying the economic gains of accurate quarter-hourly electricity price forecasts. Energy Econ. 2018, 76, 411-423. [CrossRef]

27. EPEX SPOT SE. Press Release: EPEX SPOT and ECC Successfully Reduce Lead Time on All Intraday Markets. 2015. Available online: https://www.epexspot.com/sites/default/files/download_center_files/2015-0716_EPEX\%20SPOT_Lead\%20time\%20reduction.pdf (accessed on 16 January 2020).

28. EPEX SPOT SE. Press Release: Exchange Council Approves the Introduction of 15-min Contracts on the Belgian and Dutch Market - Trading until Delivery to Be Launched on the German Market on 14 June 2017. 2017. Available online: https://www.epexspot.com/sites/default/files/download_center_files/170612_ EPEX\%20SPOT_Exchange\%20Council.pdf (accessed on 16 January 2020).

29. Li, W.; Paraschiv, F. Modelling the Evolution of Wind and Solar Power Infeed Forecasts. 2020. Available online: https:/ / ssrn.com/abstract=3600775 (accessed on 16 July 2020).

30. European Energy Exchange AG. EPEX SPOT DE/AT 15-min Continuous Intraday Market Transaction Data. 2016. Available online: https:/ / www.eex.com (accessed on 16 July 2016).

31. European Energy Exchange AG. EPEX SPOT DE 15-min Intraday Auction Market Data. 2016. Available online: https: / / www.eex.com (accessed on 16 July 2016).

32. EWE TRADING GmbH. Intradaily Updated Forecast Data of Wind and Solar Power Generation. 2016. Available online: https: / / www.ewe.com (accessed on 16 July 2016).

33. European Network of Transmission System Operators for Electricity Transparency Platform. Day-Ahead Total Load Forecast Data. 2016. Available online: https:/ / transparency.entsoe.eu (accessed on 16 July 2016).

34. European Energy Exchange AG Transparency Platform. Available Generation Capacity Data. 2016. Available online: https: / / www.eex-transparency.com (accessed on 16 July 2016).

35. Balardy, C. An Empirical Analysis of the Bid-Ask Spread in the German Power Continuous Market. 2018. Available online: http:/ / www.ceem-dauphine.org/assets/wp/pdf/0918-CEEM_Working_Paper_35_Clara_ BALARDY.pdf (accessed on 31 March 2020). 
36. Kremer, M.; Benth, F.E.; Felten, B.; Kiesel, R. Volatility and liquidity on high-frequency electricity futures markets: Empirical analysis and stochastic modeling. Int. J. Theor. Appl. Financ. 2020, 23, 2050027. [CrossRef]

37. Hansen, B.E. Sample splitting and threshold estimation. Econometrica 2000, 68, 575-603. [CrossRef]

38. Kremer, M. thrreg: Threshold Regression Model. 2020. R package version 0.1.1. Available online: https:/ / github.com/mlkremer/thrreg (accessed on 28 July 2020).

(C) 2020 by the authors. Licensee MDPI, Basel, Switzerland. This article is an open access article distributed under the terms and conditions of the Creative Commons Attribution (CC BY) license (http:/ / creativecommons.org/licenses/by/4.0/). 